\title{
Artículo Original / Original Article Effect of Huangkui on mouse podocytes under high glucose environment
}

[Efecto de Huangkui en podocitos de ratón en un entorno de glucosa alta]

Chun-Li Yu, Xiu-Li Fei, Ding-Zhong Tang, Kun Liu \& Min Zhou

Department of Renal Medicine, Jinshan Branch of Shanghai Sixth People's Hospital, Shanghai, China

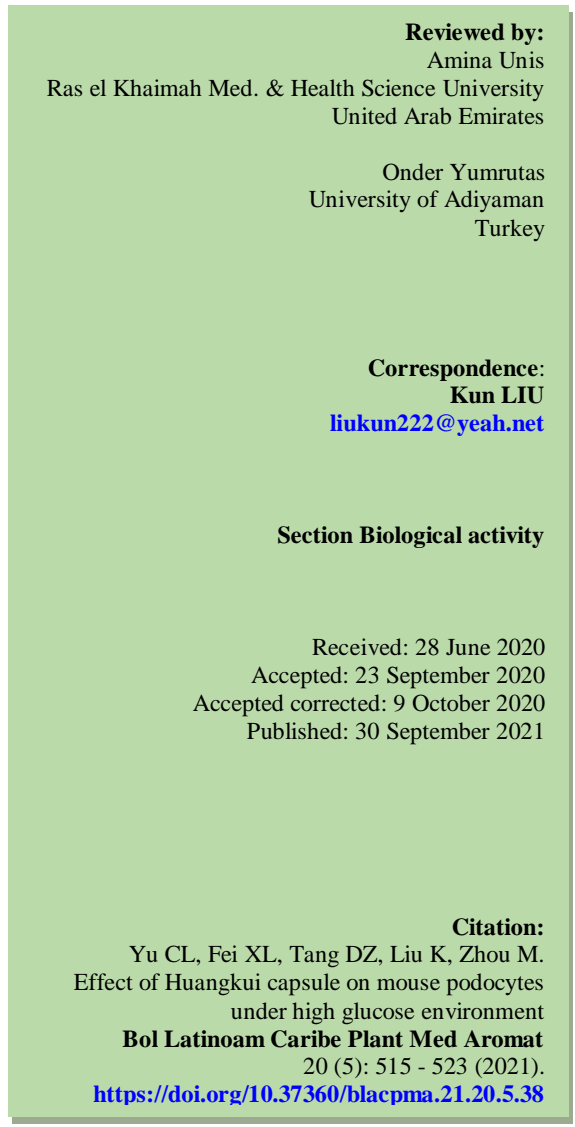

Abstract: To explore a new underlying molecular mechanism of Huangkui Extract Powder (HKEP) in the alleviation of diabetic nephropathy (DN). Murine immortalized podocytes were divided into (i) normal glucose (NG, $5.6 \mathrm{mM}$ ), (ii) NG + HKEP (0.45 g/L), (iii) $\mathrm{HG}$, and (iv) HG + HKEP (0.45 g/L) groups. MTT assay and flow cytometry were used to detect the podocyte proliferation, apoptosis and cell cycle. Cell viability was inhibited, and apoptosis increased in (iii) HG group compared with (i) NG group $(p<0.05)$. mRNA and protein expression of nephrin and podocin significantly decreased in (iii) HG group compared with (i) NG group ( $p<0.05$ ). When compared with (iii) HG group, (iv) HG + HKEP group had higher cell viability, lower apoptotic rate and higher mRNA and protein expression of nephrin and podocin $(p<0.05)$. HKEP can attenuate HG-induced podocyte damage, which may be one of the mechanisms of HKEP for attenuating DN.

Keywords: Huangkui Extract powder (HKEP); Diabetic nephropathy; Podocytes; Nephrin; Podocin.
Resumen: Explorar un nuevo mecanismo molecular subyacente del extracto del polvo de Huangkui (HKEP) en el alivio de la nefropatía diabética (ND). Los podocitos murinos inmortalizados se dividieron en (i) grupos de glucosa normal (NG, 5,6 mM), (ii) NG + HKEP (0,45 g/L), (iii) HG y (iv) HG + HKEP $(0,45 \mathrm{~g} / \mathrm{L})$. Se utilizaron el ensayo MTT y la citometría de flujo para detectar la proliferación de podocitos, la apoptosis y el ciclo celular. La viabilidad celular se inhibió y la apoptosis aumentó en el grupo (iii) $\mathrm{HG}$ en comparación con el grupo (i) NG $(p<0,05)$. La expresión de ARNm y proteínas de nefrina y podocina disminuyó significativamente en el grupo (iii) HG en comparación con el grupo (i) NG $(p<0,05)$. En comparación con el grupo (iii) HG, el grupo (iv) HG + HKEP tuvo una mayor viabilidad celular, una tasa de apoptosis más baja y una expresión de ARNm y proteínas más altas de nefrina y podocina $(p<0,05)$. HKEP puede atenuar el daño de los podocitos inducido por $\mathrm{HG}$, que puede ser uno de los mecanismos de HKEP para atenuar la DN.

Palabras clave: Polvo de extracto de Huangkui (HKEP); Nefropatía diabética; Podocitos; Nefrina; Podocina. 


\section{INTRODUCTION}

Diabetic nephropathy (DN) is one of the most serious and common chronic complications of diabetes, and presents as the leading cause of end-stage renal disease (Renal data System, 1998; Zimmet et al., 2001). Thus, timely diagnosis and treatment are of significant importance in precluding and mitigating the disease progression of DN patients. Many patients continue to progress towards the end stage of renal disease due to the lack of effective treatments. Dialysis and kidney transplantation remains as the only available treatments at present. However, both dialysis and kidney transplantation cause huge social and economic impacts. Therefore, there is an urgent need to find a new therapeutic strategy. Previous studies have reported that glomerular hemodynamic abnormalities, glomerular mesangial matrix proliferation (Noth et al., 1989), and the abnormal structure of the basement membrane (Bondar et al., 2007) are the main mechanisms of DN development. Recent studies have confirmed that glomerular podocyte apoptosis plays a key role in early DN progression (Isermann et al., 2007), and this also provides a new potential strategy for the prevention and treatment of early DN. In the process of DN, the glomerulus and its various inherent cells would undergo morphological and functional changes, and podocyte damage, which include foot process fusion (Chen et al., 2017), decrease of podocyte number or density (Xu et al., 2010), and podocyte apoptosis (Daehn et al., 2014), is closely associated with proteinuria. These pathological changes are not only the important factors in DN progression, but also key targets for Chinese and Western drug treatment. This makes it possible to seek for appropriate drug treatment alternatives for dialysis or kidney transplantation. Huangkui (HK) extract powder is a Chinese modern patent medicine extracted from Abelmoschus manihot (L.) medic. This has been widely applied in clinical therapy for improving renal inflammation and glomerular injury in chronic kidney diseases (CKD), including nephrotic syndrome, purpura nephritis, diabetic nephropathy and membranous nephropathy (Hugo et al., 1996; Menini et al., 2007; Suleiman et al., 2017; Garg, 2018). In the present study, the protective effect of $\mathrm{HK}$ on mouse podocytes under high glucose (HG) conditions was investigated by observing the podocyte activity, cell cycle and apoptosis, as well as the expression of nephrin and podocin, using 3-(4,5Dimethylthiazol-2-yl)-2,5-diphenyltetrazolium bromide (MTT) assay, flow cytometry, reverse transcription quantitative real-time polymerase chain reaction (RT-qPCR) and western blot (WB) analysis. The present study indicates that $\mathrm{HK}$ is a promising strategy for DN.

\section{MATERIALS AND METHODS Reagents}

HK extract powders (purity >99\%; Shanghai Winherb Medical Technology Co., Ltd., Shanghai, China); RPMI-1640 medium, trypsin and fetal bovine serum (FBS) (Hyclone Corporation, Shanghai, China); recombinant mouse $\gamma$-interferon (Peprotech, Rocky Hill, NJ, USA); Trizol reagent (Invitrogen Inc., Carlsbad, CA, USA); RT-PCR kit and SYBRP remix ExTaq (Dalian Bao Biological Engineering Co., Ltd., Dalian, China); Rabbit anti-nephrin (Santa Cruz Biotechnology, Shanghai, China); Rabbit antipodocin, rabbit anti- $\beta$-actin and horseradish peroxidase (HRP)-labeled goat anti-rabbit IgG (Beijing Biosscn Company, Beijing, China). All primers were synthesized by Shanghai Sangong Biotechnology Co., Ltd. (Shanghai, China).

\section{Cell culture and grouping}

The conditionally immortalized murine podocytes (MPC5) cell line was purchased from Shanghai $\mathrm{Fu}$ Heng Biotechnology Co., Ltd. After routine resuscitation, these cells were cultured in RPMI 1640 medium, containing 10\% FBS and recombinant mouse $\gamma$-interferon, in culture flasks with a floor space of $25 \mathrm{~cm}^{2}$ and $5 \% \mathrm{CO}^{2}$ at $33^{\circ} \mathrm{C}$. Then, the culture medium was regularly replaced. When these cells were fused to approximatley $80 \%$, the concentration of $\gamma$-interferon in the medium was gradually reduced until no addition was made.

Next, cells proliferated at $33^{\circ} \mathrm{C}$, and differentiated for $10-14$ days at $37^{\circ} \mathrm{C}$ in a $5 \% \mathrm{CO}^{2}$ incubator, when the cell fusion reached $20 \%-30 \%$. Then, these cells were digested and transferred to a glass bottom dish. All podocytes were synchronized with serum-free medium for 24 hours. The podocytes in good growth condition were seeded on collagen Itreated plates. When these grew to $60 \%-70 \%$ confluence, these cells were synchronized with medium containing 1\% FBS for 24 hours. The podocytes were treated with normal glucose (NG, 5.6 $\mathrm{mmol} / \mathrm{L})$ and $\mathrm{HG}(25 \mathrm{mmol} / \mathrm{L})$ in the absence or presence of the $\mathrm{HK}$ extract powder $(0.45 \mathrm{~g} / \mathrm{L})$ [12]. The podocytes were divided into the following treatments: (i) $\mathrm{NG}$, (ii), $\mathrm{NG}+\mathrm{HK}$, (iii) $\mathrm{HG}$ and (iv) $\mathrm{HG}+\mathrm{HK}$.

\section{MTT assay}

The MTT cell proliferation and cytotoxicity assay kit 
(Cat. No. E606334, Sangon Biotech [Shanghai] Co., Ltd., China) was used to measure the cell viability in each group. According to the instruction manual of the MTT assay kit, the experimental operations were as follows: Seed cells at a density of $2 \times 10^{3}$ cells/well for the cell proliferation assay and $5 \times 10^{3}$ cells/well for the cell cytotoxicity assay in a 100-ul cell culture medium in a 96-well plate. According to the experimental requirements, different concentrations of HK extract powder and podocytes were cultured for 24 hours in a humidified incubator, and subsequently incubated with $10 \mu \mathrm{l}$ of MTT reagent $(0.5 \mathrm{mg} / \mathrm{ml})$, which was added to each well $\left(37^{\circ} \mathrm{C}\right.$, $5 \% \mathrm{CO}^{2}$ ) for four hours. Subsequently, the MTT solution was removed, and $100 \mu \mathrm{l}$ of Formazan solubilization solution was added to each well. After shaking at room temperature for 10 minutes, the absorbance at $570 \mathrm{~nm}$ was measured using an ELISA reader (Thorm Multiskan Mk3, USA) to evaluate the cell viability.

\section{Apoptosis assay}

The cell apoptosis were detected using an Annexin V-fluorescein isothiocyanate (FITC) apoptosis detection kit (Cat. No. C1063; Beyotime Institute of Biotechnology), according to manufacturer's instructions. These cells were seeded in 6-well plates at a density of $1 \times 10^{5}$ cells/well in DMEM medium for 24 hours. Then, these cells were digested with $0.25 \%$ trypsin (Invitrogen Life Technologies), resuspended in $300 \mu \mathrm{l}$ of binding buffer (Beyotime Institute of Biotechnology), containing $5 \mu \mathrm{L}$ of Annexin V-FITC and $5 \mu \mathrm{L}$ of propidium iodide (PI) solution, and incubated at room temperature in the dark for 20 minutes. Afterwards, the stained cells were analyzed by flow cytometry (FACScan; BD Biosciences, Franklin Lakes, NJ, USA).

\section{Cell cycle assay}

The cell cycle assay was analyzed using a BD Cycletest $^{\mathrm{TM}}$ Plus DNA Reagent kit (BD Biosciences), according to manufacturer's instructions. Briefly, cells $\left(1 \times 10^{6}\right)$ were seeded into each well of the 6-well plate, and incubated for 24 hours for cell adhesion. Then, these cells were treated with different stimulation factors. After incubation for 24 hours, these cells were harvested and fixed with ice-cold $70 \%$ ethanol $(5 \mathrm{~mL})$ at $-20^{\circ} \mathrm{C}$ for two hours. Prior to analysis, these cells were washed with cold PBS, and re-suspended in $400 \mu \mathrm{L}$ of PBS, $20 \mu \mathrm{L}$ of PI and 20 $\mu \mathrm{L}$ of RNase A. PI was added and incubated at $4^{\circ} \mathrm{C}$ in a protected-light environment for 10 minutes. The
DNA contents were recorded by flow cytometry (Becton Dickinson, San Jose, CA, USA) equipped with the Cell Quest software.

\section{$R T-q P C R$}

Total RNA was extracted using the RNeasy Mini Kit (QIAGEN, Valencia, CA, USA), according to manufacturer's instructions. The RNA concentrations were determined using a UV spectrophotometer at an absorbance ratio of 260-280 $\mathrm{nm}$ (A260/280). The RT reactions were carried out using the Reverse Transcriptase System (Promega, Madison, WI, USA) in a $20-\mu \mathrm{L}$ reaction volume at $42^{\circ} \mathrm{C}$ for 60 minutes using a polymerase chain reaction (PCR) machine (Hangzhou Jingle Scientific Instrument Co. Ltd., Hangzhou, China). All quantitative PCR (qPCR) experiments were performed on a real-time PCR machine (Bio-Rad Laboratories) with the QuantiTect SYBR Green PCR kit and the gene-specific primers purchased from QIAGEN (Hilden, Germany). The quantification of the gene expression was assessed using the comparative cycle threshold $(\mathrm{Ct})$ method. The relative amounts of mRNA for the target genes were determined by subtracting the $\mathrm{Ct}$ values for these genes from the $\mathrm{Ct}$ value for the housekeeping gene $\beta$-actin $(\Delta \mathrm{Ct})$. The data are depicted as $2-\Delta \mathrm{Ct}$. For each primer sequence: nephrin forward: CATTATGCTCCCACCATCCGT, nephrin reverse: GTCTTCCCCCAGTCTCTCCCA; podocin forward: GGCTGAGATTCTGTCGGGCAC, podocin reverse: CTGGTTTGGAGGAACTTGGGT; $\beta$-actin forward: GTGGGGCGCCCCAGGCACCA, $\beta$-actin reverse: GTCCTTAATGTCACGCACGATTTC.

\section{Western blot}

Cells were lysed in cold lysis buffer $(50 \mathrm{mM}$ of Tris, $150 \mathrm{mM}$ of $\mathrm{NaCl}, \quad 10 \mathrm{mM}$ of ethylenediaminetetraacetic acid, and $1 \%$ Triton X100) containing protease and phosphatase inhibitors. Briefly, these proteins were separated on $10 \%$ sodium dodecyl sulfate-polyacrylamide gel electrophoresis (SDS-PAGE) gels, and subsequently transferred onto nitrocellulose membranes. The primary antibodies against nephrin $(1: 4,000)$ and podocin $(1: 4,000)$ were purchased from Santa Cruz Biotechnology. Horseradish peroxidase-conjugated antiimmunoglobulin (Ig) $\mathrm{G}$ was used as the secondary antibody (Beijing Zhongshan Golden Bridge Biotechnology Co., Ltd., Beijing, China). The blots were detected using the enhanced chemiluminescence (ECL) system (Beijing Zhongshan Golden Bridge Biotechnology Co., Ltd.). 


\section{Statistical analysis}

The data are presented as the mean \pm standard deviation (SD) of at least three independent experiments. The significance of the differences between groups was determined by multiple sample comparison methods analysis of variance (ANOVA). $p<0.05$ was considered statistically significant.

\section{RESULTS}

\section{The HK toxicity experiment}

In the preliminary experiment, the podocytes (MPC5) were treated for 24 and 42 hours with six different concentrations of $\mathrm{HK}$ extract powders $(0,0.3,0.6$, $0.9,1.2$ and $1.5 \mathrm{~g} / \mathrm{L})$. The pre-experimental results revealed that the growth state of podocytes was poor after 42 hours of treatment at various concentrations. However, after the podocytes were treated for 24 hours, the cells grew well, and exhibited significant differences among the different treatment concentrations. Therefore, the treatment at 24 hours was used as the processing time of the experiment. MTT assay was used to detect the toxicity of HK on MPC5 podocytes. It was found that the low concentration of HK promoted MPC5 proliferation under HG conditions, and this reached a peak at a concentration of $0.45 \mathrm{~g} / \mathrm{L}$. As concentration increased, the proliferative capacity of MPC5 gradually decreased. When the concentration was 1.5 $\mathrm{g} / \mathrm{L}$, the proliferative capacity returned to the baseline level. Thus, $0.45 \mathrm{~g} / \mathrm{L}$ of $\mathrm{HK}$ was selected for the follow-up study due to its least toxicity to MPC5 (Figure No. 1).

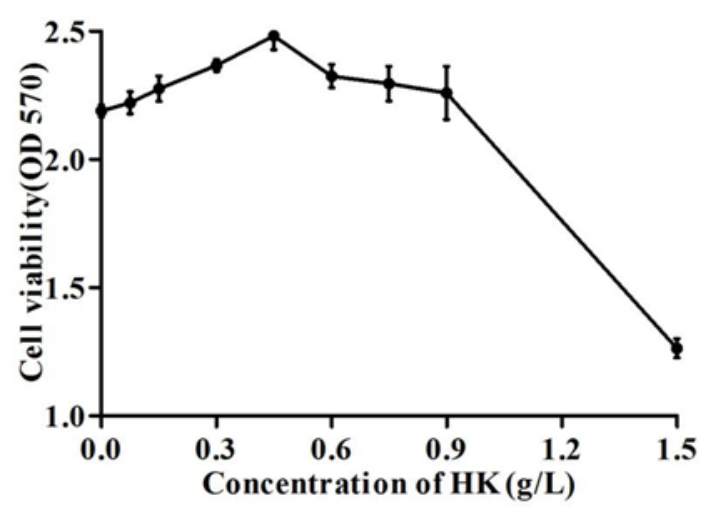

Figure No. 1

Effects of different concentrations of $\mathrm{HK}$ on MPC5 proliferation under HG conditions. The enumeration data was expressed as the mean \pm SD and analyzed by $t$ test. The experiments were repeated three times. HK, Huangkui Extract powder; HG, high glucose

\section{Effects of HK on podocyte morphology in the $H G$ environment}

The podocyte morphology in HG conditions was observed under an inverted microscope. The images revealed that under the $5.6 \mathrm{mM}$ of $\mathrm{NG}$ treatment, the podocytes were evenly distributed, basically covered the field of vision, and were mostly branched, welldifferentiated and connected by the dendritic processes. However, after $25 \mathrm{mM}$ of $\mathrm{HG}$ treatment, the podocytes grew poorly, decreased in quantity, and changed in morphology, with the foot processing shortened and partially turning elliptic. Under the combined treatment of $\mathrm{HG}$ and $\mathrm{HK}$, the number of podocytes recovered, and exhibited no significant difference from the group treated with NG (Figure No. 2).
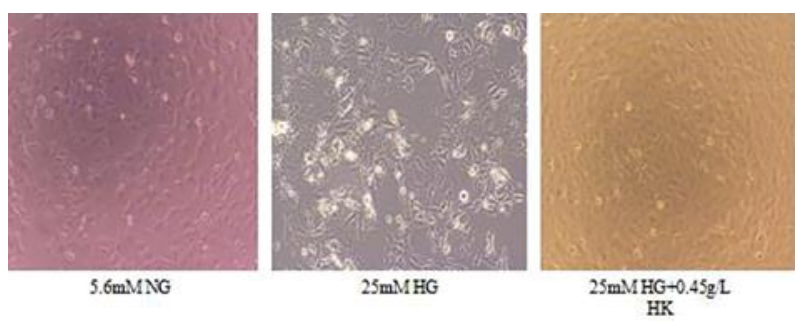

Figure No. 2

HK protects podocytes from morphology damage in HG environment observed by inverted microscope. The experiments were repeated three times. HK, Huangkui Extract powder; HG, high glucose; NG, normal glucose

\section{Effects of HK on podocyte proliferation in the $H G$ environment}

MTT assay was used to detect the effect of HK on podocyte proliferation under $\mathrm{HG}$ conditions, in order to understand the effect of different D-glucose and HK concentrations on podocyte activity. In the present experiment, MTT assay was used to detect the podocyte activity under different treatment conditions. The experimental results revealed that more significant changes in cell viability in different D-glucose treatment conditions were observed after 24 hours of treatment, when compared to those after 48 hours of treatment. After 24 hours of treatment, the podocyte vitality significantly decreased in the 25-mM HG group, when compared with the 5.6-mM $\mathrm{NG}$ group $(p<0.05)$, while the podocyte vitality significantly increased in the $25-\mathrm{mM} \mathrm{HG}+0.45-\mathrm{g} / \mathrm{L}$ HK groups, when compared to the $25-\mathrm{mM}$ HG group $(p<0.01)$ (Figure No. 3). These results show that the HG concentration treatment inhibited the activity of podocytes after 24 hours of treatment, and that HK 
impoved the podocyte proliferation in the $\mathrm{HG}$ environment.

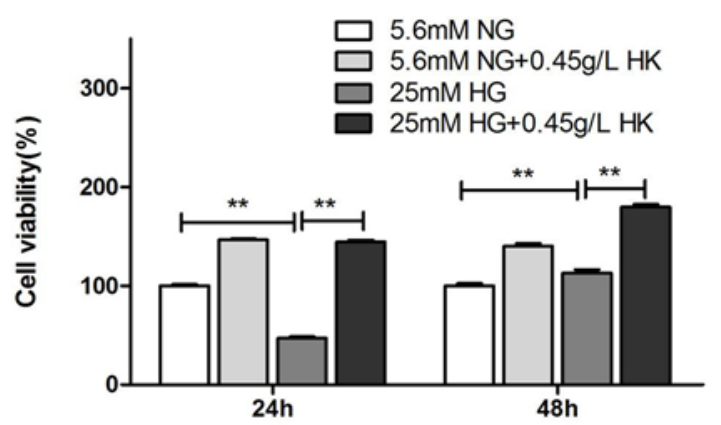

Figure No. 3

Effects of $\mathrm{HK}$ on podocyte proliferation in HG environment. The measurement data, was expressed as mean \pm SD and analyzed by. single factor analysis. The experiment was repeated three times. HK, Huangkui Extract powder; HG, high glucose; NG, normal glucose
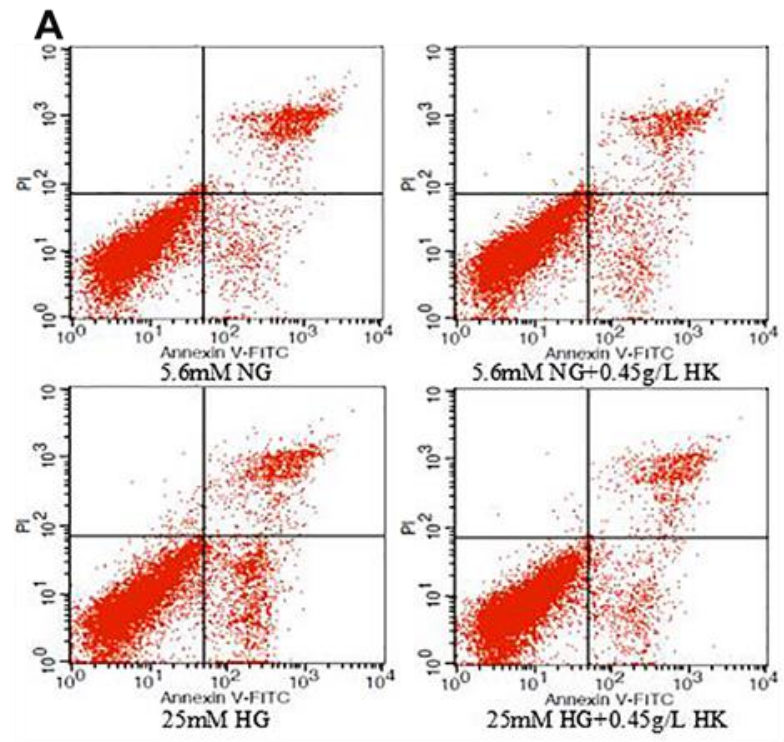

Effects of HK on podocyte apoptosis under the HG environment

The podocyte apoptosis in the HG environment was evaluated by flow cytometry, and the results demonstrated that compared with the 5.6-mM NG, the apoptosis rate significantly increased in $25-\mathrm{mM}$ HG $(p<0.05)$. These results show that podocyte apoptosis was induced by the HG. In addition, the apoptosis rate of podocytes significantly decreased $(p<0.01$, Figure No. 4B) in the $25-\mathrm{mM} \mathrm{HG}+0.45-$ $\mathrm{g} / \mathrm{L}$ HK group, when compared to the $25-\mathrm{mM} \mathrm{HG}$ group. These shows that the increase in apoptosis in podocytes was induced by the $\mathrm{HG}$, and that the improvement of the HK extract powder on apoptosis was obvious (all, $p<0.05$; Figure No. 4 ).

B

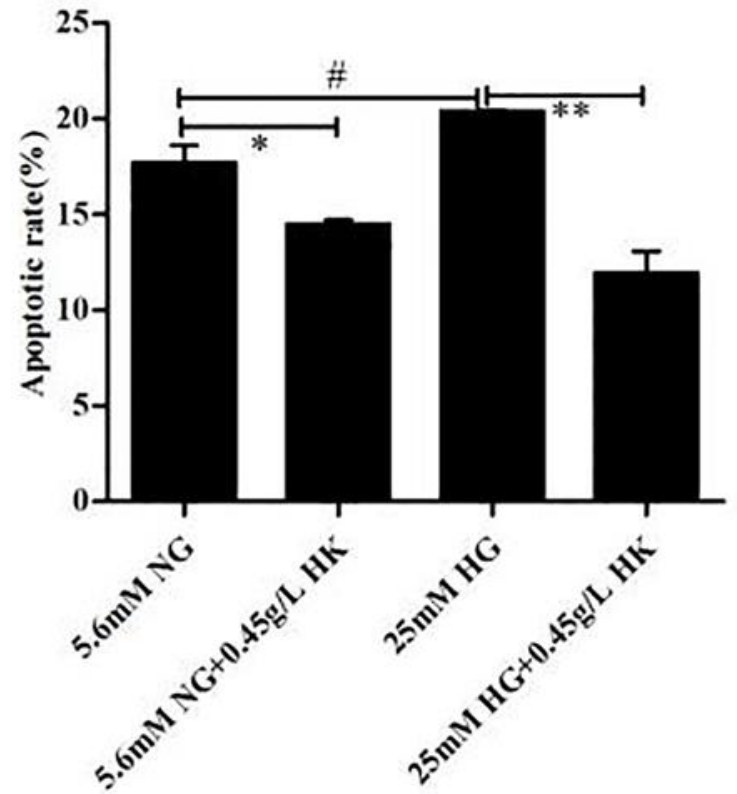

Figure No. 4

Effects of HK on podocyte apoptosis in HG environment

A, detection of podocyte apoptosis by flow cytometry; B, Quantitative statistics of podocyte apoptosis rate; * indicates $p<0.05$ when $5.6 \mathrm{mM}$ NG group VS. $5.6 \mathrm{mM} \mathrm{NG}+0.45 \mathrm{~g} / \mathrm{L}$ HK group, $25 \mathrm{mM}$ HG group VS. 25

mM HG + 0.45g/L HK group; \# indicates $p<0.05$ when $5.6 \mathrm{mM}$ NG group VS $25 \mathrm{mM}$ HG group. The measurement data, wasexpressed as standard deviation \pm mean and analyzed by. single factor analysis. The experiment was repeated three times. HK, Huangkui Extract powder, HG, high glucose. 
Effects of $\mathrm{HK}$ on the podocyte cell cycle in the $H G$ environment

The podocyte cell cycle in the HG environment was analyzed by flow cytometry, and the results suggested that compared with the 5.6-mM NG group, the 5.6-mM NG + $0.45-\mathrm{g} / \mathrm{L}$ HK group exhibited a decreased number in the G1/G2 phase and an increased number in the $\mathrm{S}$ phase. These are consistent with the results in the $25-\mathrm{mM} \mathrm{HG}+0.45-\mathrm{g} / \mathrm{L} \mathrm{HK}$ group, when compared with the $25-\mathrm{mM}$ HG group (all, $p<0.05$; Figure No. 5).

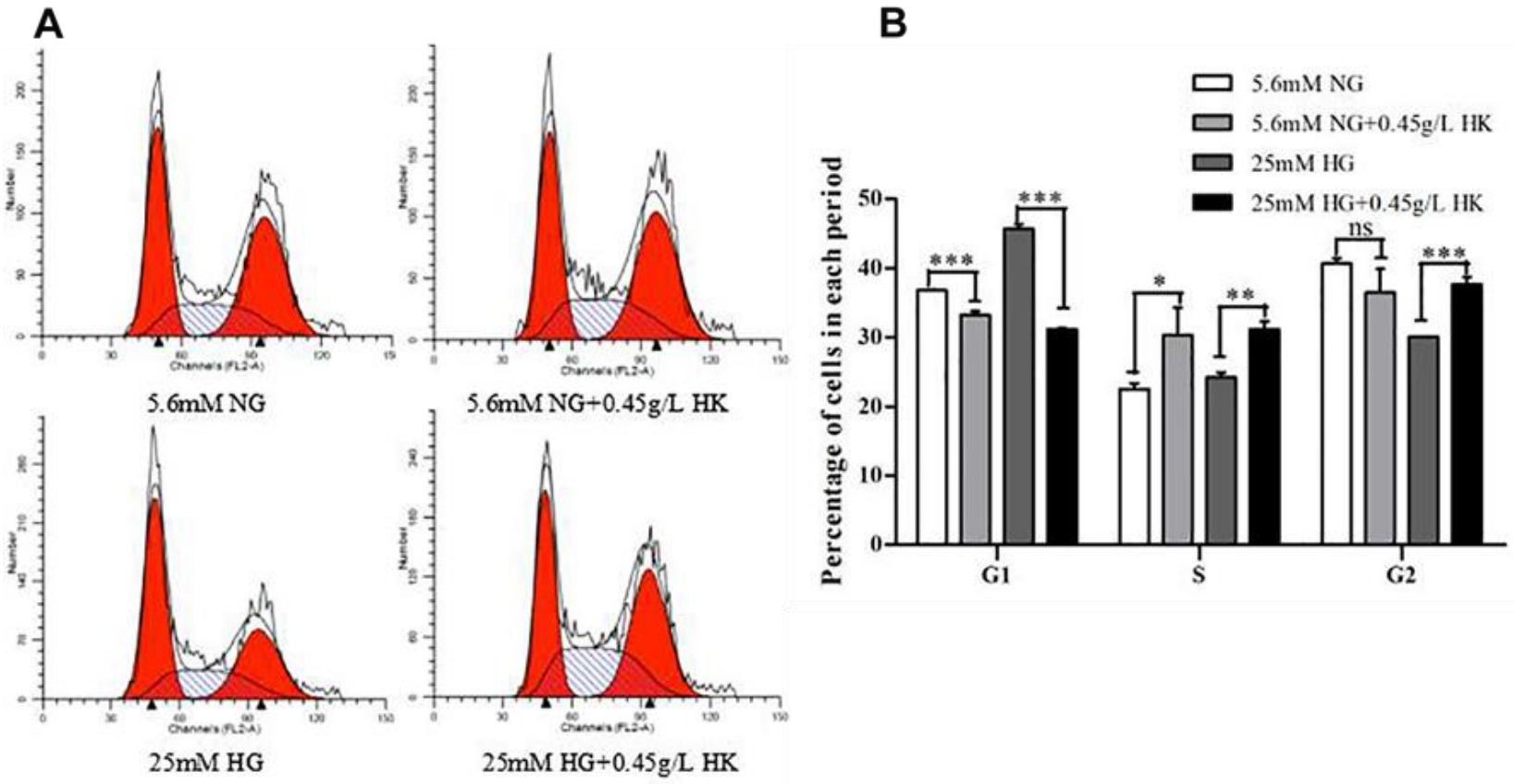

Figure No. 5

Effects of HK on podocyte cell cycle in HG environment

A: detection of podocyte cell cycle by flow cytometry; B: quantitative statistics of cell percentage in G1, S, and $\mathrm{G} 2$ phases. The measurement data, was expressed as standard deviation \pm mean and analyzed by single factor analysis. The experiment was repeated three times. HK, Huangkui Extract powder; HG, high glucose; NG, normal glucose. ns indicates no significant difference; * indicates $p<0.05$; ** indicates $p<0.01$; ***indicates $p<0.001$

Effects of HK on the expression of nephrin and podocin in podocytes under the HG environment RT-qPCR and western blot were performed to evaluate the effects of $\mathrm{HK}$ on the mRNA and protein expression of nephrin and podocin in the $\mathrm{HG}$ environment. Under the treatment of HG, the nephrin and podocin expression levels significantly decreased, when compared to the NG-treated group $(p<0.01$, Figures No. 6A \& 6B). In addition, the influence of $\mathrm{HK}$ on nephrin and podocin expression was further analyzed. The results revealed that the mRNA and protein expression of nephrin and podocin significantly decreased in the $25-\mathrm{mM} \mathrm{HG}$ group, when compared to the 5.6-mM NG group, while the mRNA and protein expression of nephrin and podocin significantly increased in the $25-\mathrm{mM}$ $\mathrm{HG}+0.45-\mathrm{g} / \mathrm{L}$ HK group, when compared to the 25$\mathrm{mM}$ HG group $(p<0.05$, Figures No. 6A \& 6B). The results of the present study demonstrate that $\mathrm{HG}$ conditions reduced the nephrin and podocin expression in cultured mouse podocytes, while the HK extract powder promoted the expression of nephrin and podocin under high D-glucose. 
A

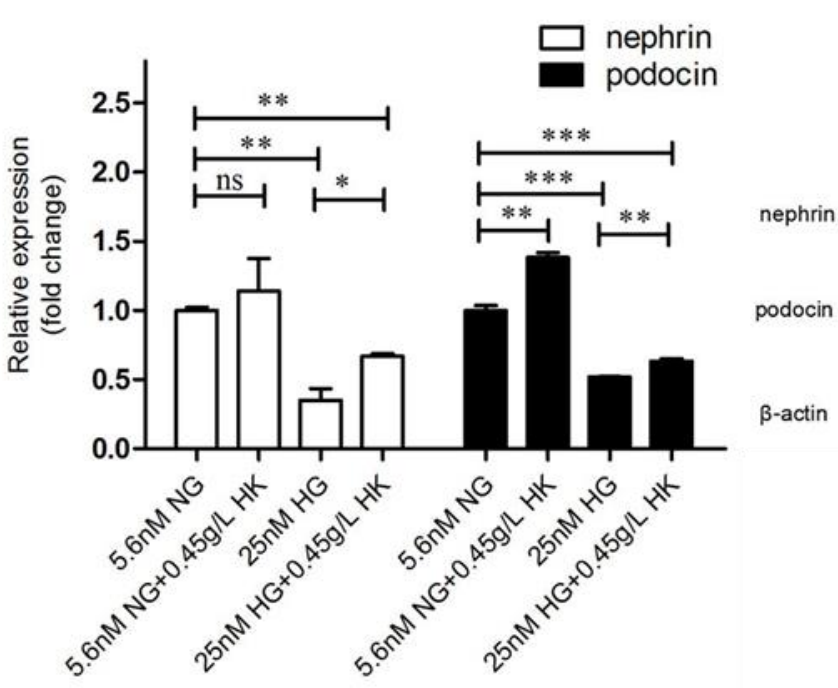

B

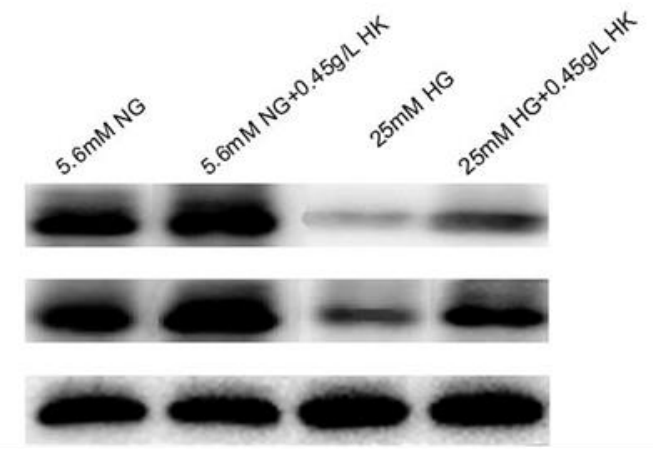

Figure No. 6

Effects of HK on the expressions of nephrin and podocin in podocytes under HG conditions

A, the mRNA expressions of nephrin and podocin determined by RT-qPCR; B, the protein expression of nephrin and podocin determined by Western blot analysis. * indicates $p<0.05$. The measurement data, was expressed as standard deviation \pm mean and analyzed by single factor analysis. The experiment was repeated three times. HK, Huangkui Extract powder; HG, high glucose; NG, normal glucose

\section{DISCUSSION}

With the improvement of living standards, the incidence of diabetes in China has continuously increased year by year. DN remains as one of the leading causes of death in diabetic patients, and has a higher morbidity (up to $70 \%$ ) with the prolongation of diabetes. Recent studies have revealed that glomerular dysfunction is correlated to the development of DN (Carney, 2017), and that the podocytic process intersect each other to form the outermost layer of the glomerular filtration barrier $(\mathrm{Li}$ et al., 2004). Changes in the podocytic process actin structural skeleton cause changes in the glomerular filtration barrier (Horinouchi et al., 2003; Li et al., 2004), and the decreased number and apoptosis of podocytes induce compensatory structural changes in the remaining podocytes, leading to filtration barrier dysfunction, the occurrence of proteinuria, and leakage of the plasma proteins (Huber et al., 2001). Glomerular podocytes are important cells that prevent the leakage of proteins. Podocyte proteins, especially nephrin and podocin, which locate in the septum area of the hiatus fissure, are the key molecular proteins that prevent albumin filtration. Nephrin is a core component of the podocyte slit diaphragm, and its expression at the cell surface is critical for maintaining the glomerular filtration barrier. Furthermore, nephrin is not only an adhesion molecule, but also a signal transduction molecule involved in the signal transduction of podocytes (Kramer et al., 2003). The mutations of nephrin cause severe congenital proteinuria and renal failure (Romero-Aroca et al., 2017). Podocin is a recently discovered transmembrane protein, which acts as an integral component of the glomerular fissure diaphragm, and is involved in cytoskeleton connections (Dai et al., 2017). Once podocin mutates, it causes a large amount of proteinuria (Dai et al., 2017). The involvement of nephrin and podocin in the transduction of intracellular signals has been demonstrated, and podocin enhances the nephrininduced downstream signal transduction (Liu et al., 2005; Chen et al., 2012). Previous studies have revealed that there is no excretion of nephrin in normal human urine, while nephrin excretion significantly increases in the urine of patients with a history of diabetes of more than 10 years, which has a positive correlation with the ratio of urinary albumin/creatinine (Song \& Lian, 2005; Tu et al., 2013). When the kidney is stimulated by HG or other

Boletín Latinoamericano y del Caribe de Plantas Medicinales y Aromáticas/521 
harmful stimuli, the changes in nephrin and podocin proteins would destroy the integrity of the glomerular filtration membrane, such as the molecular and electrostatic barrier, further resulting in massive protein leakage, glioblastoma multiforme (GBM) apoptosis and exfliation, glomerular sclerosis, and finally, the formation of end-stage DN (Han et al., 2019). The therapeutic drug used in the present study, the HK extract powder, is an extract of Abelmoschus manihot (L.) medic, which improves $\mathrm{DN}$ by activating the peroxisome proliferator-activated receptor (PPAR)- $\alpha / \gamma$ and attenuating endoplasmic reticulum stress (Pagtalunan et al., 1997), and prevents tubulointerstitial fibrosis in chronic renal failure (CRF) rat involvement in the action mechanism of inhibiting the NADPH oxidase/ROS/ERK pathway (Kwoh et al., 2006).
In summary, the present study revealed that in the HG environment, the podocytes exhibited the decreased proliferation, increased apoptosis, arrest in the G1 phase, and down-regulated expression of nephrin and podocin protein. Fortunately, these above symptoms were effectively ameliorated after HK intervention. This suggests that HK may protect glomerular podocytes by upregulating the nephrin and podocin expression.

\section{ACKNOWLEDGEMENTS}

Fund project: Shanghai Jinshan key specialty construction Foundation Project (NO. JSZK2015A07); Shanghai Jinshan Medical Health Class Science and Technology Innovation Fund Project (NO. 2017-3-11).

\section{REFERENCES}

Bondar IA, Klimontov VV, Nadeev AP. 2007. Urinary excretion of proinflammatory cytokines and transforming growth factor beta at early stages of diabetic nephropathy. Terapevticheskii Arkhiv 80: 52 - 56.

Cai HD, Su SL, Qian DW, Guo S, Tao WW, Cong XD, Tang R, Duan JA. 2017. Renal protective effect and action mechanism of Huangkui capsule and its main five flavonoids. J Ethnopharmacol 206: 152 - 159. https://doi.org/10.1016/j.jep.2017.02.046

Carney EF. 2017. Podocytes: ShcA regulates nephrin turnover. Nat Rev Nephrol 13: 722. https://doi.org/10.1038/nrneph.2017.153

Chen P, Wan Y, Wang C, Zhao Q, Wei Q, Tu Y, Yin X. 2012. Mechanisms and effects of Abelmoschus manihot preparations in treating chronic kidney disease. Zhongguo Zhong Yao Za Zhi 37: 2252 - 2256.

Chen X, Qin Y, Zhou T, Jiang L, Lei F, Qin H, Zhang L, Zhou Z. 2017. The potential role of retinoic acid receptor alpha on glomerulosclerosis in rats and podocytes injury is associated with the induction of MMP2 and MMP9. Acta Biochim Biophys Sin 49: 669 - 679. https://doi.org/10.1093/abbs/gmx066

Daehn I, Casalena G, Zhang T, Shi S, Fenninger F, Barasch N, Yu L, D'Agati V, Schlondorff D, Kriz W, Haraldsson B, Bottinger EP. 2014. Endothelial mitochondrial oxidative stress determines podocyte depletion in segmental glomerulosclerosis. J Clin Invest 124: 1608 - 1621.

https://doi.org/10.1172/jci71195

Garg P. 2018. A review of podocyte biology. Am J Nephrol 47: 3 - 13. https://doi.org/10.1159/000481633

Ge J, Miao JJ, Sun XY, Yu JY. 2016. Huangkui capsule, an extract from Abelmoschus manihot (L.) medic, improves diabetic nephropathy via activating peroxisome proliferator-activated receptor (PPAR)alpha/gamma and attenuating endoplasmic reticulum stress in rats. J Ethnopharmacol 189: 238 - 249. https://doi.org/10.1016/j.jep.2016.05.033

Horinouchi I, Nakazato H, Kawano T, Iyama K, Furuse A, Arizono K, Machida J, Sakamoto T, Endo F, Hattori S. 2003. In situ evaluation of podocin in normal and glomerular diseases. Kidney Int 64: 2092 - 2099. https://doi.org/10.1046/j.1523-1755.2003.00303.x

Huber TB, Kottgen M, Schilling B, Walz G, Benzing T. 2001. Interaction with podocin facilitates nephrin signaling. J Biol Chem 276: 41543 - 41546. https://doi.org/10.1074/jbc.c100452200

Hugo C, Hugo C, Pichler R, Gordon K, Schmidt R, Amieva M, Couser WG, Furthmayr H, Johnson RJ. 1996. The cytoskeletal linking proteins, moesin and radixin, are upregulated by platelet-derived growth factor, but not basic fibroblast growth factor in experimental mesangial proliferative glomerulonephritis. J Clin Invest 97: 2499 - 2508. https://doi.org/10.1172/jci118697

Isermann B, Vinnikov IA, Madhusudhan T, Herzog S, Kashif M, Blautzik J, Corat MA, Zeier M, Blessing E, Oh J, Gerlitz B, Berg DT, Grinnell BW, Chavakis T, Esmon CT, Weiler H, Bierhaus A, Nawroth PP. 2007. Activated protein $\mathrm{C}$ protects against diabetic nephropathy by inhibiting endothelial and podocyte apoptosis. Nat Med 13: 1349 - 1358. https://doi.org/10.1038/nm1667 
Kramer HJ, Nguyen QD, Curhan G, Hsu CY. 2003. Renal insufficiency in the absence of albuminuria and retinopathy among adults with type 2 diabetes mellitus. JAMA 289: 3273 - 3277. https://doi.org/10.1001/jama.289.24.3273

Li H, Lemay S, Aoudjit L, Kawachi H, Takano T. 2004. SRC-family kinase Fyn phosphorylates the cytoplasmic domain of nephrin and modulates its interaction with podocin. J Am Soc Nephrol 15: 3006 - 3015. https://doi.org/10.1097/01.asn.0000146689.88078.80

Liu Z, Liu S, Zhou L, Gao X, Ju W, Tan H, Yang C. 2012. Effects of HuangKui capsules on glibenclamide pharmacokinetics in rats. J Ethnopharmacol 139: 1 - 5. https://doi.org/10.1016/j.jep.2011.03.043

Menini S, Iacobini C, Oddi G, Ricci C, Simonelli P, Fallucca S, Grattarola M, Pugliese F, Pesce C, Pugliese G. 2007. Increased glomerular cell (podocyte) apoptosis in rats with streptozotocin-induced diabetes mellitus: role in the development of diabetic glomerular disease. Diabetologia 50: 2591 - 2599. https://doi.org/10.1007/s00125-007-0821-y

Noth RH, Krolewski AS, Kaysen GA, Meyer TW, Schambelan M. 1989. Diabetic nephropathy: hemodynamic basis and implications for disease management. Ann Intern Med 110: 795 - 813. https://doi.org/10.7326/0003-4819-110-10-795

Pagtalunan ME, Miller PL, Jumping-Eagle S, Nelson RG, Myers BD, Rennke HG, Coplon NS, Sun L, Meyer TW. 1997. Podocyte loss and progressive glomerular injury in type II diabetes. J Clin Invest 99: 342 - 348. https://doi.org/10.1172/jci119163

Renal Data System. 1998. USRDS 1998 annual data report (NIH Publ. No. 98-3176). US Government printing office, Washington, USA.

Romero-Aroca P, Baget-Bernaldiz M, Navarro-Gil R, Moreno-Ribas A, Valls-Mateu A, Sagarra-Alamo R, BarrotDe La Puente JF, Mundet-Tuduri X. 2018. Glomerular filtration rate and/or ratio of urine albumin to creatinine as markers for diabetic retinopathy: A ten-year follow-up study. J Diabetes Res 2018: 5637130. https://doi.org/10.1155/2018/5637130

Kwoh C, Shannon MB, Miner JH, Shaw A. 2006. Pathogenesis of nonimmune glomerulopathies. Annu Rev Pathol 1: 349 - 374. https://doi.org/10.1146/annurev.pathol.1.110304.100119

Song GZ, Lian YG. 2005. 20 cases of IgA nephropathy treated-major by Huangkui capsule. J New Chin Med 37: 78.

Suleiman HY, Roth R, Jain S, Heuser JE, Shaw AS, Miner JH. 2017. Injury-induced actin cytoskeleton reorganization in podocytes revealed by super-resolution microscopy. JCI Insight 2. 94137. https://doi.org/10.1172/jci.insight.94137

Tu Y, Sun W, Wan YG, Che XY, Pu HP, Yin XJ, Chen HL, Meng XJ, Huang YR, Shi XM. 2013. Huangkui capsule, an extract from Abelmoschus manihot (L.) medic, ameliorates adriamycin-induced renal inflammation and glomerular injury via inhibiting p38MAPK signaling pathway activity in rats. J Ethnopharmacol 147: 311 - 320. https://doi.org/10.1016/j.jep.2013.03.006

Xu L, Yang HC, Hao CM, Lin ST, Gu Y, Ma J. 2010. Podocyte number predicts progression of proteinuria in IgA nephropathy. Mod Pathol 23: 1241 - 1250. https://doi.org/10.1038/modpathol.2010.110

Zimmet P, Alberti KG, Shaw J. 2001. Global and societal implications of the diabetes epidemic. Nature 414: 782 787. https://doi.org/10.1038/414782a 